\title{
Post-Hospital Syndrome and Hyponatremia
}

\author{
José Bellod-Tondaㅁ, Julio Blázquez-Encinar², María Dolores Jover-Ríos ${ }^{3}$, \\ Carmen Seguí-Pérez ${ }^{4}$, Juan Méndez-Mora ${ }^{5}$, Francisco Caparrós-Hernández ${ }^{5}$, \\ Álex Méndez-Jover ${ }^{5}$, Marc Seguí-Pérez ${ }^{5}$, David Baláž¹, Leticia Espinosa del Barrio', \\ Jesús Corbacho-Redondo1, Carles García-Cervera', Juan Manuel Núñez-Cruz ${ }^{1}$, \\ Isidro Hernández-Isasi' ${ }^{1}$, Javier Guzmán-Martínez1 ${ }^{1}$ Angie Gómez-Uranga1, \\ Pedro Esteve-Atiénzar1, Jorge Peris-García ${ }^{1,6}$, Veronica Martínez-Sempere ${ }^{1}$, \\ Eliana Damonte-White1, Óscar Hernando Ruiz-Ariza7, Juan Carlos López-Corbalán" ${ }^{8}$, \\ Lourdes Lajara-Villar1, Andrea Riaño-Pérez¹, Paloma Chazarra-Pérez ${ }^{1}$, \\ María Escamilla-Espínola1, Maria Luisa Asensio-Tomás', Miguel Ángel Auladell-Alemany, \\ Laura Serna-Torres' ${ }^{1}$, Asunción Pérez-Fullana5, Amparo Gómez-Siurana9, \\ Sergio Menargues-Irles ${ }^{9}$, José Miguel Seguí-Ripoll1,6*
}

\footnotetext{
${ }^{1}$ Internal Medicine Department, University Hospital of San Juan, Alicante, Spain

${ }^{2}$ Internal Medicine Department, Torrevieja University Hospital, Alicante, Spain

${ }^{3}$ Internal Medicine Department, Hospital La Vega Baja of Orihuela, Alicante, Spain

${ }^{4} \mathrm{CEU}$ Cardinal Herrera, University Veterinary Hospital, Valencia, Spain

${ }^{5}$ Secondary School, Marist Brothers High School, Alicante, Spain

${ }^{6}$ Department of Clinical Medicine, Miguel Hernández University, Elche, Spain

${ }^{7}$ Primary Care Medicine, Benilloba, Spain

${ }^{8}$ Sub-Delegation of the Government, Alicante, Spain

${ }^{9}$ Chemical Engineering Department, University of Alicante, Alicante, Spain

Email: *jsegui@umh.es
}

How to cite this paper: Bellod-Tonda, J. Blázquez-Encinar, J., Jover-Ríos, M.D., Seguí-Pérez, C., Méndez-Mora, J., Caparrós-Hernández, F., Méndez-Jover, Á., Seguí-Pérez, M., Baláž, D., del Barrio, L.E., Corbacho-Redondo, J., García-Cervera, C., Núñez-Cruz, J.M., Hernández-Isasi, I., Guzmán-Martínez, J., Gómez-Uranga, A., Esteve-Atiénzar, P., Peris-García, J., Martínez-Sempere, V., Damonte-White, E., Ruiz-Ariza, Ó.H., López-Corbalán, J.C., Lajara-Villar, L., Riaño-Pérez, A., Chazarra-Pérez, P., Escamilla-Espínola, M., Asensio-Tomás, M.L., Auladell-Alemany, M.Á., Serna-Torres, L., Pérez-Fullana, A., Gómez-Siurana, A., Menargues-Irles, S. and Seguí-Ripoll, J.M. (2021) Post-Hospital Syndrome and Hyponatremia. Health, 13, 846-856.

https://doi.org/10.4236/health.2021.138065

\begin{abstract}
Introduction: Post-hospital syndrome (PHS) is defined as a period of vulnerability during the first 30 days after a patient is discharged from hospital, in which multiple factors come into play. Hyponatremia is the most frequent hydroelectrolytic disorder in hospitalized patients and may be related to the appearance of PHS. Objective: The objective is to estimate the prevalence of PHS that is assessed as the rate of readmissions in the first 30 days after discharge, in patients with hyponatremia. Material and Methods: It is a descriptive observational study of patients with hyponatremia who were discharged from 1 September 2010 to 2 February 2020 at the Internal Medicine Service of the Hospital University of San Juan (Alicante, Spain). Results: Of the 25 included patients, 5 (20\%) were readmitted within a month of discharge, after a mean of 11.4 days (standard deviation [SD] 5.1). The overall mortality of the study was $20 \%(n=5)$, with one case of death in the first 30 days post-hospitalization (4\%). In 12 patients (48\%) the origin of the
\end{abstract}


Received: July 9, 2021

Accepted: August 17, 2021

Published: August 20, 2021

Copyright $\odot 2021$ by author(s) and Scientific Research Publishing Inc. This work is licensed under the Creative Commons Attribution International License (CC BY 4.0).

http://creativecommons.org/licenses/by/4.0/ hyponatremia was undetermined. The most frequently recorded etiology for the condition was pharmacological $(\mathrm{n}=7,28 \%)$, and there was pronounced variability in its clinical and laboratory study. The most widely used corrective measure was drug withdrawal, in 16 patients (64\%). Water intake restriction was the most common treatment after discharge (5 patients, $20 \%$ ), followed by urea ( 2 patients, $8 \%$ ), while tolvaptan was not used. Conclusion: Hyponatremia may be the cause of PHS, which could increase the rate of early readmission. Hyponatremia is an underdiagnosed and undertreated entity, so it is necessary to apply an appropriate system to optimize its management and, in future studies, to assess its impact on PHS.

\section{Keywords}

Hospitalization, Hyponatremia, Patient Readmission, Inappropriate ADH Syndrome

\section{Introduction}

The term "post-hospitalization syndrome" (PHS), first coined by Krumkohlz, is used to describe the set of symptoms that can appear in the first 30 days following hospital discharge, a period marked by greater vulnerability and a higher risk of complications and readmission [1].

Numerous studies have analyzed functional deterioration in patients after a hospital stay, especially in frail older people and immediately after discharge. Covinsky et al. [2] defined hospital-associated disability as the exacerbation of baseline disability following a hospital stay. The negative impact of hospitalization has been studied from different perspectives and is associated with a high risk in both the development and the worsening of disabilities, especially in older people [3] [4]. Other authors have also described the appearance of unfavorable health events in up to $62 \%$ of patients between the first and third months post-discharge [5].

In PHS, $19.6 \%$ of patients require re-hospitalization within 30 days [6]. Although researchers have tried to identify predictive factors for this outcome, there is still no completely validated model to promptly detect patients at greater risk [7]. Among the factors known to be associated with higher readmission rates in the early period, post-discharge is the failure to recover normal levels of serum albumin [8], low pre-admission autonomy in the basic activities of daily living, diminished autonomy during the hospital stay [9], certain comorbidities, and previous hospitalizations. Age is described as the main risk factor determining the deterioration from the baseline state, but its direct impact on readmissions is not as clear.

Certain factors related to the hospital stay itself can also favor the appearance of PHS. Many stressors are inherent to hospital admission: altered sleep habits, poor adaptation to a new environment, a large number of different professionals 
involved in care, medication, pain, iatrogenic complications, forced immobility, and inadequate diet. Thus, a multifactorial perspective is required to study PHS in order to better predict the risk in each patient.

Inpatients often present metabolic or hydroelectrolytic alterations, the most frequent of which is hyponatremia in the general as well as inpatient population, with an estimated in-hospital incidence of 1 per 100 patients per day and a prevalence of around 2.5\% [10] [11]. However, this disorder is underdiagnosed and underreported, despite constituting an analytic alteration, so these data probably underestimate the real prevalence.

There are many mechanisms involved in PHS affecting sympathetic activity, immune function, metabolism, coagulation, nutritional status, disturbance of sleep, physical functioning and coordination, pain and other discomforts. As a result, all those mechanisms may be associated during hospital stay with many different types of stressors (modify the circadian rhythm and sleep quality, multiple blood tests, constant alarm noises...). Additionally, the high complexity of the majority of patients attended in our Internal Medicine Service (multiple comorbidities) associated with the aging of the population (elderly and very elderly above 80 years are the most vulnerable to the PHS) increase the occurrence of stressors, suggesting the possibility we have inadvertently been causing harm to these patients during hospitalization [12] [13].

Hyponatremia is associated with greater in-hospital mortality, reaching up to $20 \%$ in severe cases compared to less than $10 \%$ in patients who do not develop this disorder, and this risk remains high after discharge [14]. The condition also entails a higher risk of admission to the intensive care unit, a longer length of stay, and greater hospitalization costs [15]. The risk of readmission is also high in patients with hyponatremia [16], and can be related to some common conditions (excessive hydration, chronic comorbidities decompensation, use of several medications and polypharmacy...), however, there is a need for more information clarifying the link between this entity and PHS.

The aim of this study is to assess the importance of hyponatremia in PHS in terms of one-month readmission rates following discharge from the internal medicine ward in patients with hyponatremia on admission, during the hospital stay, or at discharge. We hypothesized that hyponatremia would be associated with a high incidence of PHS. Secondary aims were to describe the characteristics of patients with hyponatremia, the diagnostic process and clinical management of the condition, and the mean interval from discharge to readmission and/or death.

\section{Material and Methods}

This descriptive, observational, longitudinal, retrospective study took place in the internal medicine ward of the University Hospital of San Juan (Alicante, Spain) and included all patients discharged from 1 September 2010 to 2 February 2020 and whose discharge report included the diagnostic code for hyponatremia 
(whether on admission, during the hospital stay, or at discharge). We excluded patients who died during their hospital stay or were transferred to another center or service.

The Orion Clinic hospital database was used to identify patients meeting inclusion criteria during the study period, on request to the hospital's clinical records department. Clinical histories were reviewed to collect demographic variables; clinico-analytical parameters; and details on diagnosis and treatment at admission, during the hospital stay, at discharge and on readmission. Data were fully anonymized and confidential.

For the descriptive statistical analysis, we calculated absolute and relative frequencies for the categorical variables and the mean, standard deviation (SD), and range of the quantitative variables.

\section{Results}

A total of 25 patients were discharged from the internal medicine service during the study period, including 20 women (80\%) and 5 men (20\%). All were white, and their age ranged from 69 years to 95 years (mean 82.3 SD 7.7).

Daily data on readmissions were collected for 30 days post-discharge in the included patients. Median length of stay was 4.1 days (SD 2.2, range 1-9). The most frequent comorbidities were hypertension $(\mathrm{n}=22,88 \%)$, dyslipidemia $(\mathrm{n}=$ $12,48 \%)$, and type 2 diabetes mellitus $(\mathrm{n}=11,44 \%)$ (Table 1$)$. The etiology of the hyponatremia was unknown in nearly half the patients $(\mathrm{n}=12,48 \%)$; in the rest, the most common cause was pharmacological treatments $(n=7,28 \%)$, which in three cases $(12 \%)$ were diuretics.

Pain, at any location, was the most frequent symptom on readmission $(\mathrm{n}=12$, $48 \%)$, followed by dizziness and vomiting $(\mathrm{n}=9,36 \%)$ and nausea $(\mathrm{n}=5,20 \%)$. At discharge, the only symptom recorded was pain $(n=2,8 \%)$. No differences in symptoms were observed when patients were split into two groups based on blood sodium levels ( $\geq 120 \mathrm{mmol} / \mathrm{L}$ versus $<120 \mathrm{mmol} / \mathrm{L}$ ). The principal diagnoses were hypoosmolar hyponatremia $(\mathrm{n}=4,16 \%)$ along with moderate $(\mathrm{n}=3$, $12 \%)$ and severe $(\mathrm{n}=3,12 \%)$ hyponatremia.

The most commonly used treatments were angiotensin II receptor antagonists (ARA-II, $\mathrm{n}=15,60 \%$ ), proton bomb inhibitors (PBI, $\mathrm{n}=11,44 \%$ ), loop diuretics $(\mathrm{n}=10,40 \%)$, and beta-blockers $(\mathrm{n}=12,48 \%)$. However, grouped by families, the antihypertensive drugs ARA-II along with angiotensin-converting-enzyme inhibitors (ACE inhibitors) were used in 20 patients (80\%), and diuretics-whether alone or in combination, in 15 (60\%).

The parameters collected in this study are presented in Figure 1 and Table 2: $\left[\mathrm{Na}^{+}\right]_{\mathrm{O}}$ and $\left[\mathrm{K}^{+}\right]_{\mathrm{O}}$ were collected in 16 patients (64\%); urine osmolality, thyroid stimulating hormone (THS), and free thyroxine (FT4), in 15 (60\%); plasma osmolality, in 14 (56\%); plasma cortisol, in 7 (28\%); and adrenocorticotropic hormone (ACTH), in 2 (8\%).

Among the measures administered to correct the hyponatremia at discharge (Table 3), treatments were modified in 18 patients (72\%). Medications that can 
potentially cause hyponatremia were withdrawn in 16 patients (64\%), especially ARA-IIs $(n=7)$ as well as the antidepressant selective serotonin reuptake inhibitors (SSRI) and thiazides ( $\mathrm{n}=3$ each), ACE inhibitors and anticonvulsants $(\mathrm{n}=$ 2 each). Other modifications included water intake restrictions $(n=5,20 \%)$ and

Table 1. Comorbidities, etiology, and clinical, diagnostic, and treatment characteristics of included patients.

\begin{tabular}{|c|c|c|c|}
\hline Comorbidities & n (\%) & Etiology & n (\%) \\
\hline Hypertension & $22(88)$ & Unknown & $12(48)$ \\
\hline Diabetes & $11(44)$ & SIADH & \\
\hline Dyslipidemia & $12(48)$ & Medication-induced & $8(32)$ \\
\hline Ischemic cardiopathy & $2(8)$ & Idiopathic & $2(8)$ \\
\hline Heart failure & $5(20)$ & Vomiting & $1(4)$ \\
\hline Kidney failure & $7(28)$ & Multifactorial & $2(8)$ \\
\hline Acute COPD & $1(4)$ & & \\
\hline Signs and symptoms, $\mathrm{n}(\%)$ & Admission & Hospitalization & Discharge \\
\hline Pain & $12(48 \%)$ & $3(12 \%)$ & $2(8 \%)$ \\
\hline Nausea & $5(20 \%)$ & 0 & 0 \\
\hline Diarrhea & $4(16 \%)$ & 0 & 0 \\
\hline Agitation & $2(8 \%)$ & $2(8 \%)$ & 0 \\
\hline Dizziness & $9(36 \%)$ & 0 & 0 \\
\hline Confusion & $4(16 \%)$ & $2(8 \%)$ & 0 \\
\hline Falls & $4(16 \%)$ & 0 & 0 \\
\hline Diagnosis & $\mathrm{n}(\%)$ & Treatment & n (\%) \\
\hline Hyponatremia & & ARA-II & $15(60)$ \\
\hline Unknown origin & $2(8)$ & ACE inhibitors & $5(20)$ \\
\hline Hypovolemic & $1(4)$ & Beta-blockers & $12(48)$ \\
\hline Hypoosmolar & $4(16)$ & Proton bomb inhibitor & $11(44)$ \\
\hline Mild & $1(4)$ & Loop diuretics & $10(40)$ \\
\hline Moderate & $3(12)$ & Thiazides & $6(24)$ \\
\hline Severe & $3(12)$ & SSRI & $5(20)$ \\
\hline Pharmacological hypotension & $1(4)$ & Aldosterone antagonists & $2(8)$ \\
\hline Constitutional syndrome & $2(8)$ & Anticonvulsants & $4(16)$ \\
\hline Ogilvie syndrome & $1(4)$ & & \\
\hline Fever & $1(4)$ & & \\
\hline SIADH & $1(4)$ & & \\
\hline Kidney failure & $1(4)$ & & \\
\hline Vomiting & $1(4)$ & & \\
\hline Respiratory failure & $2(8)$ & & \\
\hline
\end{tabular}

ACE inhibitor: angiotensin-converting-enzyme inhibitor; ARA-II: angiotensin II receptor antagonists; COPD: chronic obstructive pulmonary disease; SIADH: syndrome of inappropriate antidiuretic hormone secretion; SSRI: selective serotonin reuptake inhibitors. 
administration of urea $(n=2,8 \%)$. Tolvaptan treatment was not used in any of the cases.

Six patients were discharged with hyponatremia (mean blood sodium 132.5 SD $1.6 \mathrm{mmol} / \mathrm{L}$ ), which they had developed during their hospital stay. Five (20\%) of these patients were readmitted within 30 days of discharge; five had

Table 2. Mean values of basic analytical parameters in participants with hyponatremia.

\begin{tabular}{cccc}
\hline \multirow{2}{*}{$\begin{array}{c}\text { Analytical } \\
\text { parameter }\end{array}$} & \multicolumn{3}{c}{ Mean (SD) } \\
\cline { 2 - 4 } & Admission & Hospitalization & Discharge \\
\hline$\left[\mathrm{Na}^{+}\right]_{\mathrm{P}}(\mathrm{mmol} / \mathrm{L})$ & $123.44(6.51)$ & $128.32(5.55)$ & $132.46(6.98)$ \\
{$\left[\mathrm{Na}^{+}\right]_{\mathrm{O}}(\mathrm{mmol} / \mathrm{L})$} & $49.44(36.05)$ & $61.17(45.10)$ & $65.14(33.85)$ \\
{$\left[\mathrm{K}^{+}\right]_{\mathrm{O}}(\mathrm{mmol} / \mathrm{L})$} & $46.22(26.35)$ & $25.50(16.33)$ & $21.68(8.21)$ \\
Osm & $264(23.40)$ & $267.25(16.45)$ & $274.11(11.01)$ \\
$\mathrm{Osm}_{\mathrm{O}}(\mathrm{mOsm} / \mathrm{Kg})$ & $440.83(122.14)$ & $354.29(167.50)$ & $328.85(156.43)$ \\
\hline
\end{tabular}

SD: standard deviation.

Table 3. Routine treatment and treatment at discharge.

\begin{tabular}{ccc}
\hline Treatment & Routine, $\mathbf{n}(\%)$ & At discharge, $\mathbf{n}(\%)$ \\
\hline Loop diuretics & $10(40)$ & $7(28)$ \\
Thiazides & $6(24)$ & $3(12)$ \\
Aldosterone antagonists & $2(8)$ & $1(4)$ \\
ACE inhibitors & $5(20)$ & $3(12)$ \\
ARA-II & $15(60)$ & $8(32)$ \\
Beta-blockers & $12(48)$ & $12(48)$ \\
Proton bomb inhibitors & $11(44)$ & $10(40)$ \\
Anticonvulsants & $4(16)$ & $2(8)$ \\
SSRIs & $5(20)$ & $2(8)$ \\
Water restrictions & $0(0)$ & $5(20)$ \\
Urea & $0(0)$ & $2(8)$ \\
Tolvaptan & $0(0)$ & $0(0)$ \\
\hline
\end{tabular}

ACE inhibitor: angiotensin-converting-enzyme inhibitor; ARA-II: angiotensin II receptor antagonists; SSRI: selective serotonin reuptake inhibitors.

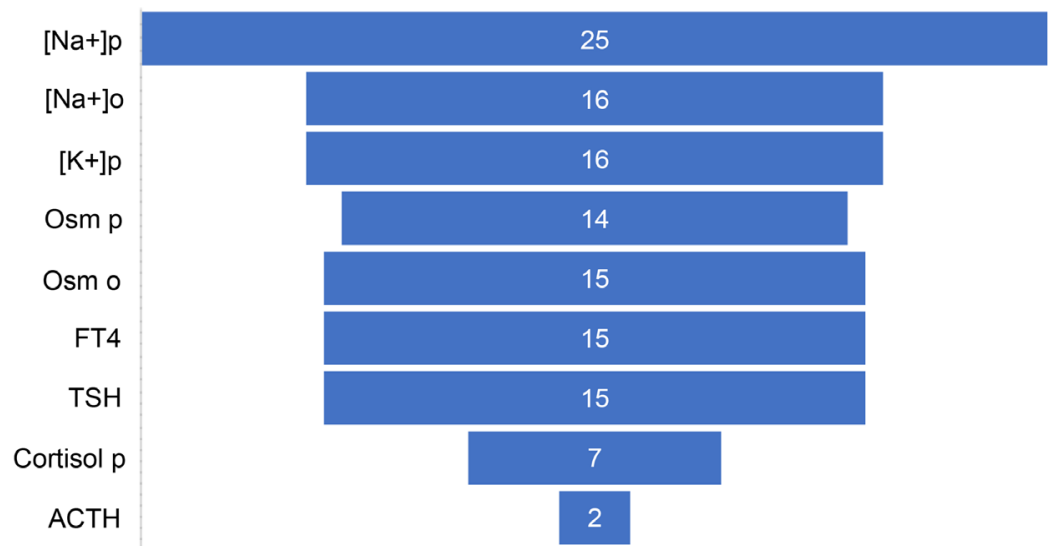

Figure 1. Analytical parameters tested in the sample of patients with hyponatremia. 
been advised to restrict water intake to $1 \mathrm{~L} /$ day, and two were given urea (15 $\mathrm{mg} / 12 \mathrm{~h}$ ). Mean blood sodium at readmission was $126.8 \mathrm{mmol} / \mathrm{L}$ (SD 3.4). The mean interval from discharge to readmission was 11.4 days (SD 5.1, range 5-19). Patients' mean age was 77.6 years (SD 6.6), and heart failure was the cause of readmission in 2 of the patients (33\%). All in all, five patients $(20 \%)$ died during follow-up, including one within a month of discharge and four more in the following five months.

\section{Discussion}

This descriptive, observational, longitudinal and retrospective study involved 25 patients with hyponatremia who had been discharged from the internal medicine ward at our hospital. We wanted to determine whether hyponatremia was related to a higher rate of $\mathrm{PHS}$, as assessed through the readmission rate in the first 30 days from discharge.

The one-month readmission rate in our sample was $20 \%$, a result in concordance with the literature (19.6\%). Our results suggest that hyponatremia may have an influence on PHS, independently of the rest of the comorbidities, carrying a higher risk compared to readmission rates reported in normonatremia. The mean discharge-readmission interval, of 11.4 days, is consistent with the description of early vulnerability following hospitalization and highlights the importance of the transition from the hospital to home within the first month of discharge.

Diuretics are one of the most frequent causes of hyponatremia [17] [18], especially thiazides (more than $60 \%$ of patients on these drugs present hyponatremia) but also loop diuretics [19]. Hyponatremia is also associated with the use of SSRIs (about $32 \%$ of patients on SSRIs develop SIADH) and some antiepileptic drugs $(40 \%$ SIADH). The results of our study are concordant with other published research, and explain the measures adopted: diuretics and antidepressants were proportionally among the most frequently withdrawn drugs.

Heart failure is responsible for up to $23 \%$ of the cases of hyponatremia, similar to our results $(20 \%)$, despite our small sample size. Patients with heart failure have also been shown to carry an increased risk of readmission, as observed in our series, with a one-month readmission rate of $50 \%$. Nevertheless, although some authors have proposed a causal relationship, other concomitant etiological factors should also be considered [20].

The cause of hyponatremia was unknown in nearly half of our patients $(n=$ $12,48 \%)$, reflecting the scarce diagnostic attention and characterization of this entity. In our series, for example, SIADH was diagnosed in one patient $(\mathrm{n}=1$, $4 \%)$ and noted as a possibility in one over the course of six months. The most frequent qualifier for hyponatremia was "hypoosmolar" ( $\mathrm{n}=4,16 \%)$ with levels of $\mathrm{Osm}_{\mathrm{O}}$ of more than $100 \mathrm{mOsm} / \mathrm{kg}$ and $\left[\mathrm{Na}^{+}\right]_{\mathrm{O}}$ of more than $30 \mathrm{mmol} / \mathrm{L}$. All of these characteristics could indicate undiagnosed SIADH, which could have an impact on PHS due to hyponatremia and on treatment at discharge. 
According to European guidelines [21], hyponatremia should be addressed first by measuring $\mathrm{Osm}_{\mathrm{p}}$ to rule out non-hypotonic hyponatremia. From there, the patient should undergo assessment for $\mathrm{Osm}_{\mathrm{O}},\left[\mathrm{Na}^{+}\right]_{\mathrm{O}}$ and extracellular volume (ECV), which enables the classification of the hyponatremia as hypotonic with normal, elevated, or low ECV. This classification can orient the etiology. Clinically, it is important to assess the severity of the symptomology and the time since onset. SIADH is a diagnosis of exclusion, determined when a series of criteria are met, including the determination of $\left[\mathrm{Na}^{+}\right]_{\mathrm{P}},\left[\mathrm{Na}^{+}\right]_{\mathrm{O}},\left[\mathrm{K}^{+}\right]_{\mathrm{O}}, \mathrm{Osm}_{\mathrm{P}}$, and $\mathrm{Osm}_{\mathrm{O}}$ as well as the exclusion of hypothyroidism and cortisol deficit. In the management of SIADH-induced euvolemic hyponatremia, it is necessary to measure the concentration of ions ( $\mathrm{Na}$ and $\mathrm{K}$ ) in urine) in order to calculate the Fürst index $\left.\left(\left[\mathrm{Na}^{+}\right]_{\mathrm{O}}+\left[\mathrm{K}^{+}\right]_{\mathrm{O}}\right) /\left[\mathrm{Na}^{+}\right]_{\mathrm{P}}\right)$, a prognostic indicator of the response to water restrictions and of the therapeutic response [22] [23]. In this study, we observed that the basic parameters for studying hyponatremia were scarcely studied. Essential parameters were measured only in some patients, including $\mathrm{Osm}_{\mathrm{p}}$ $(\mathrm{n}=14,56 \%), \operatorname{Osm}_{\mathrm{o}}(\mathrm{n}=15 ; 60 \%)$, and $\left[\mathrm{Na}^{+}\right]_{\mathrm{O}}(\mathrm{n}=16,64 \%)$. Only two patients underwent a complete study for euvolemic hypoosmolar hyponatremia even though this was the most commonly recorded type. The great variability among patients regarding the measurement of these parameters reflects the low importance given to this entity and the lack of a systematic approach in its management.

For managing hyponatremia attributed to a pharmacological origin, clinicians should suspend or change the medications responsible for causing the condition [24]. In our series, this was the most frequently applied measure $(n=16,64 \%)$, mainly affecting thiazides, anticonvulsants, and SSRIs, and highlighting that the pharmacological etiology of hyponatremia is taken into account. The specific treatments for chronic hyponatremia attributed to SIADH, as the frequent cause among inpatients [25], mainly consisted of water restrictions and to a lesser extent urea. Tolvaptan was not used at all. European guidelines as well as recommendations from international and Spanish experts agree that water intake restrictions should be the first-line treatment in non-severe cases. As an alternative or second-line intervention, European guidelines recommend the use of urea, especially in cases of SIADH. However, even though its use is accepted, the benefits of urea have not been proven in any clinical trials. Moreover, it is not considered to be a medication, it has poor palatability, and it can provoke some complications, especially in older patients (dehydration, excessive correction).

There is some controversy around the use of tolvaptan. The European guideline disadvises its use due to a low safety profile. In contrast, expert guidelines and other studies in the literature base their endorsement on published evidence of its efficacy and safety (SALT-1, SALT-2, and SALTWATER studies) [26] [27]. The algorithm of recommendations by experts in Spain also supports the use of tolvaptan.

Thus, there is a lack of consensus and specificity around both the diagnosis 
and therapeutic management of hyponatremia. This situation could generate some confusion or uncertainty in routine clinical practice, especially when deciding whether to administer a treatment appropriate for addressing SIADH of idiopathic etiology. There is a need for further studies providing scientific evidence to inform the development of a systematic diagnostic and treatment approach for hypotonic hyponatremia.

This study is the first that aims to associate hyponatremia due to any cause with PHS in a retrospective, real-world cohort. Our literature review revealed a dearth of adequate epidemiological studies, the scant clinical importance given to the entity, and its possible underdiagnosis. As a result, these patients may often be managed inappropriately and insufficiently, which could favor the development of PHS and slow or complicate their recovery following hospitalization.

Our study has some limitations. Its observational, retrospective nature, in a cohort of patients attended in a single ward by different professionals, may have influenced the variability in the diagnosis, therapeutic approach and treatment. Missing data in clinical records may have also affected the results or introduced bias. The small sample size is another limitation, which could be justified by the underreporting of hyponatremia. Strengths of the study include its focus on how hyponatremia is handled in routine clinical practice in our setting, highlighting the need to implement measures that improve its study in these patients and its impact on PHS.

\section{Conclusions}

Hyponatremia may be a cause of PHS, favoring the early readmission rate in discharged patients. Larger studies are necessary to assess the relationship between PHS and hyponatremia and to demonstrate its clinical relevance.

Hyponatremia is under-evaluated, underdiagnosed, and therefore undertreated. An adequate awareness and management of this entity are necessary to detect and correct it, enabling the medical community to reach a consensus and systematize its assessment. Further, good-quality studies are needed to provide reliable evidence.

\section{Conflicts of Interest}

The authors declare no conflicts of interest regarding the publication of this paper.

\section{References}

[1] Krumholz, H.M. (2013) Post-Hospital Syndrome-An Acquired, Transient Condition of Generalized Risk. The New England Journal of Medicine, 368, 100-102.

[2] Covinsky, K.E., Pierluissi, E. and Johnston, C.B. (2011) Hospitalization-Associated Disability "She Was Probably Able to Ambulate, But I'm Not Sure". JAMA, 306, 1782-1793.

[3] Covinsky, K.E., Palmer, R.M., Fortinsky, R.H., Counsell, S.R., Stewart, A.L., Kresevic, D., et al. (2003) Loss of Independence in Activities of Daily Living in Older 
Adults Hospitalized with Medical Illnesses: Increased Vulnerability with Age. Journal of the American Geriatrics Society, 51, 451-458. https://doi.org/10.1046/j.1532-5415.2003.51152.x

[4] Gill, T.M., Allore, H.G., Gahbauer, E.A. and Murphy, T.E. (2010) Change in Disability after Hospitalization or Restricted Activity in Older Persons. JAMA, 304, 1919-1928. https://doi.org/10.1001/jama.2010.1568

[5] Forster, A.J., Clark, H.D., Menard, A., Dupuis, N., Chernish, R., Chandok, N., et al. (2004) Adverse Events among Medical Patients after Discharge from Hospital. CMAJ, 170, 345-349.

[6] Jencks, S.F., Williams, M.V. and Coleman, E.A. (2009) Rehospitalizations among Patients in the Medicare Fee-for-Service Program. The New England Journal of Medicine, 360, 1418-1428. https://doi.org/10.1056/NEJMsa0803563

[7] Kansagara, D., Englander, H., Salanitro, A., Kagen, D., Theobald, C., Freeman, M., et al. (2011) Risk Prediction Models for Hospital Readmission: A Systematic Review. JAMA, 306, 1688-1698. https://doi.org/10.1001/jama.2011.1515

[8] Friedmann, J.M., Jensen, G.L., Smiciklas-Wright, H. and McCamish, M.A. (1997) Predicting Early Nonelective Hospital Readmission in Nutritionally Compromised Older Adults. The American Journal of Clinical Nutrition, 65, 1714-1720. https://doi.org/10.1093/ajcn/65.6.1714

[9] Tonkikh, O., Shadmi, E., Flaks-Manov, N., Hoshen, M., Balicer, R.D. and Zisberg, A. (2016) Functional Status before and during Acute Hospitalization and Readmission Risk Identification. Journal of Hospital Medicine, 11, 636-641. https://doi.org/10.1002/jhm.2595

[10] Burguera, V., Rodríguez-Palomares, J.R., Fernández-Codejón, O., Tenorio, M.T., Rey, J.M. and del Liaño, F. (2011) Epidemiología de la hiponatremia. Nefrología, 2, 13-20.

[11] Burst, V. (2019) Etiology and Epidemiology of Hyponatremia. Frontiers of Hormone Research, 52, 24-35. https://doi.org/10.1159/000493234

[12] Caraballo, C., Dharmarajan, K. and Krumholz, H.M. (2019) Post Hospital Syndrme: Is the Stress of Hospitalization Causing Harm? Revista Española de Cardiología (English Edition), 72, 896-898. https://doi.org/10.1016/j.rec.2019.04.010

[13] Goldwater, D.S., Dharmarajan, K., McEwan, B.S. and Krumholz, H.M. (2018) Is Posthospital Syndrome a Result of Hospitalization-Induced Allostatic Overload? Journal of Hospital Medicine, 13, 1-9. https://doi.org/10.12788/jhm.2986

[14] Clayton, J.A., Le Jeune, I.R. and Hall, I.P. (2006) Severe Hyponatraemia in Medical In-Patients: Aetiology, Assessment and Outcome. QJM, 99, 505-511.

https://doi.org/10.1093/qjmed/hcl071

[15] Deitelzweig, S., Amin, A., Christian, R., Friend, K., Lin, J. and Lowe, T.J. (2013) Health Care Utilization, Costs, and Readmission Rates Associated with Hyponatremia. Hospital Practice (1995), 41, 89-95. https://doi.org/10.3810/hp.2013.02.1014

[16] Corona, G., Giuliani, C., Parenti, G., Colombo, G.L., Sforza, A., Maggi, M., et al. (2016) The Economic Burden of Hyponatremia: Systematic Review and Meta-Analysis. The American Journal of Medicine, 129, 823-835.e4.

[17] Liamis, G., Milionis, H. and Elisaf, M. (2008) A Review of Drug-Induced Hyponatremia. The American Journal of Kidney Diseases, 52, 144-153. https://doi.org/10.1053/j.ajkd.2008.03.004

[18] Verbalis, J.G., Goldsmith, S.R., Greenberg, A., Korzelius, C., Schrier, R.W., Sterns, R.H., et al. (2013) Diagnosis, Evaluation, and Treatment of Hyponatremia: Expert 
Panel Recommendations. The American Journal of Medicine, 126, S1-S42.

[19] Sonnenblick, M., Friedlander, Y. and Rosin, A.J. (1993) Diuretic-Induced Sever Hyponatremia. Review and Analysis of 129 Reported Patients. Chest, 103, 601-606. https://doi.org/10.1378/chest.103.2.601

[20] Gheorgiade, M., Rossi, J.S., Cotts, W., Shin, D.D., Hellkamp, A.S., Piña, I.L., et al. (2007) Characterization and Prognostic Value of Persistent Hyponatremia in Patients with Severe Heart Failure in the ESCAPE Trial. Archives of Internal Medicine, 167, 1998-2005. https://doi.org/10.1001/archinte.167.18.1998

[21] Spasovski, G., Vanholder, R., Allolio, B., Annane, D., Ball, S., Bichet, D., et al. (2014) Clinical Practice Guideline on Diagnosis and Treatment of Hyponatraemia. European Journal of Endocrinology, 170, G1-G47.

[22] Runkle, I., Gomez-Hoyos, E., Cuesta-Hernández, M., Chafer-Vilaplana, J. and De Miguel, P. (2015) Hyponatraemia in Older Patients: A Clinical and Practical Approach. Reviews in Clinical Gerontology, 25, 31-52. https://doi.org/10.1017/S0959259814000197

[23] Mount, D.B. (2015) Trastornos Hidroelectrolíticos. In: Kasper, D.L., Fauci, A.S., Hauser, S.L., Longo, D.L., Jameson, J.L. and Loscalzo, J., Eds., Harrison. Principios de Medicina Interna, Vol. 1, 19th Edition, McGraw Hill Interamericana, México, 295-312.

[24] Woodward, M., Gonski, P., Grossmann, M., Obeid, J., Scholes, R. and Topliss, D.J. (2018) Diagnosis and Management of Hyponatraemia in the Older Patient. Internal Medicine Journal, 48, 5-12.

[25] Runkle, I., Villabona, C., Navarro, A., Pose, A., Formiga, F., Tejedor, A., et al. (2013) Tratamiento de la hiponatremia secundaria al sindrome de secrecion inadecuada de la hormona antidiuretica/algoritmo multidisciplinar. Medicina Clínica (Barc), 141, 507.e1-507.e10.

[26] Schrier, R.W., Gross, P., Gheorghiade, M., Berl, T., Verbalis, J.G., Czerwiec, F.S., et al. (2006) Tolvaptan, a Selective Oral Vasopressin V2-Receptor Antagonist, for Hyponatremia. The New England Journal of Medicine, 355, 2099-2112. https://doi.org/10.1056/NEJMoa065181

[27] Berl, T., Quittnat-Pelletier, F., Verbalis, J.G., Schrier, R.W., Bichet, D.G., Ouyang, J., et al. (2010) Oral Tolvaptan Is Safe and Effective in Chronic Hyponatremia. Journal of the American Society of Nephrology, 21, 705-712. https://doi.org/10.1681/ASN.2009080857.

\section{Abbreviations}

PHS: Post-Hospital Syndrome;

ARA-II: Angiotensin II Receptor Antagonists;

ACE Inhibitors: Angiotensin-Converting-Enzyme Inhibitors;

COPD: Chronic Obstructive Pulmonary Disease;

SSRI: Selective Serotonin Reuptake Inhibitors;

SIADH: Syndrome of Inappropriate Antidiuretic Hormone Secretion;

$\left[\mathrm{Na}^{+}\right]_{\mathrm{P}} /\left[\mathrm{Na}^{+}\right]_{\mathrm{O}}$ : Plamsa and Urine Sodium Concentration;

$\left[\mathrm{K}^{+}\right]_{\mathrm{O}}$ : Urine Potassium Concentration;

Osm $_{\mathrm{P}}: / \mathrm{Osm}_{\mathrm{O}}$ : Plasma and Urine Osmolality. 